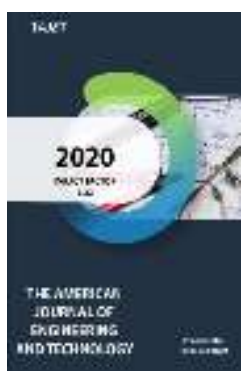

Journal Website: http://usajournalshub.c om/index,php/tajet

Copyright: Original content from this work may be used under the terms of the creative commons attributes 4.0 licence.

\section{Improving Calendar Modeling Of Array Construction Typical Low-Rise Buildings By Flow Method}

\author{
Yusupova Lobar Sidiqovna \\ Doctoral Student, Tashkent Institute Of Architecture And Civil Engineering, 100000, Navoi St., \\ 13, Tashkent, Uzbekistan \\ Mirakhmedov Makhamadjon \\ Doctor Of Technical Sciences, Prof., Tashkent State University Of Transport, 100167, \\ St.Adylkhodzhaeva, 1, Tashkent , Uzbekistan
}

\title{
ABSTRACT
}

Population growth, the compact location of villages and towns around cities, the creation of jobs on their territory makes the construction of affordable housing in rural areas relevant. In order to improve project management, in particular, to create a single platform that unites the efforts of construction participants and further reduce the cost of projects, a methodology has been proposed for developing a schedule for the construction of a complex consisting of an array of residential buildings, social infrastructure and linearly extended structures. The resulting schedule can be used to conclude contracts between construction participants and clarify financing schedules, start and end dates of stages, supply of material and technical resources to the construction site.

\section{KEYWORDS}

Affordable housing, scheduling, inline organization of construction, graphanalytic model, interaction of construction participants

\section{INTRODUCTION}

Housing in rural areas has a strategic priority in conditions of dense population density in limited areas, in particular, when rural settlements are closely adjacent to cities. The formation of demand and its structure are mainly influenced by two factors: demographic and socio-psychological, determining the long-term nature of the development of housing construction in rural areas. In Uzbekistan, a program for the construction of ready-made houses on a turnkey basis is being implemented practically at cost $[1,2]$, the relevance of which has not decreased over the past 10 years [4,6-9], being included as a priority in the "Strategy of actions for five priority areas of development of Uzbekistan in 2017-2021 ". The success of commissioning rural housing in Uzbekistan is determined by outstripping rates in comparison with the CIS countries. Thus, the annual commissioning of housing per 1000 people in rural 
areas exceeds the analogous data of Armenia by 7.0 times, Kyrgyzstan by 5.0 times, Ukraine by 3.0 times, Kazakhstan by 2.0 times and Russia - by 1.3 times [3] In 2019, 2100.1 billion soums were mastered, 15010 houses and apartments were built, and during 20172021. more than 53 thousand houses and apartments are to be built.

Currently, one-story single-family 3, 4 and 5-room houses with a higher level of comfort are being implemented with a living area of up to $72.6 \mathrm{~m}^{2} ; 78.8$ $\mathrm{m}^{2} ; 108.4 \mathrm{~m}^{2}$ respectively. Taking into account the population's need for certain types of services and social infrastructure, during the same period, 10 general education schools, 26 rural medical centers, 242 rural community centers, 319 shopping malls, 22 markets, 94 bakeries, 179 household centers were built in rural areas. services, 51 mini-banks and 113 children's sports grounds $[2,7]$.

\section{STATE OF THE ISSUE}

The construction of affordable housing for low-rise buildings is carried out according to standard projects and are complexes of residential, social, technological structures and communications, which is planned to be implemented within 10 months and requires strict coordination of the actions of the construction participants.

The function of the customer in the implementation of the program for the construction of residential buildings on a turnkey basis for standard projects in rural areas is entrusted to IK Kishlok Kurilish Invest LLC (Resolution of the Cabinet of Ministers of the Republic of Uzbekistan No. 44), attracting other participants on a contract basis based on the annual volume of the program.

Obviously, the customer, lender, contractors, organizations supplying the construction site with material and technical resources must have a unified program of action, which must be based on design decisions. The timely development of this document is designed to determine in advance the agreed terms for the entry of contractors into the construction process, the timing and amount of resource requirements by type, ultimately, to use the document when concluding agreements between the participants, thereby providing a single platform that will determine and direct the actions of all participants in the construction production facilities to achieve the goal of putting this complex on time and of the required quality, which are the result of correct financing, and together with PPR and technological maps - a tool for purposeful control over the project implementation process. In particular, the general contractor builds its relations with subcontractors and suppliers proceeding, first of all, on the basis of: the range of works, the timing of their start and end, the volume and distribution in time, the inclusion of which in the contracts between the general contractor and subcontractors will streamline their interaction at the construction site ... These parameters can be determined during the scheduling of the construction of the complex. It can be argued that the strategy for success on the construction site is laid down in the schedule if it is developed according to the norms and is subsequently used for its intended purpose [13-16].

The calendar plan is a unified information platform for organizing construction and plays an important role in organizing the interaction of construction participants [10]. With all the evidence of the stated provisions, there are significant deviations from the fulfillment of the requirements of the norms, in particular, the norms of the backlog in construction [11,12].

As noted in [13,17], the schedule represents the distribution of capital investments and construction and installation works in time, which must be linked to the norms of the construction reserve. In paragraph 6 of clause 1.2 of the textbook [17] it is directly stated that "The construction schedule is developed taking into account the norms of the construction reserve." In the current textbooks and manuals, numerous examples of forms of calendar 
plans are given, without setting out the method of how to ensure compliance with the norms of the construction reserve in the calendar plan, i.e. the methodology for developing a schedule that meets the requirements of the reserve standards is not specified in the books on scheduling and modeling $[12,13,16]$. In support of the decisions taken on the organization of construction, references are made to regulatory documents without the presentation of backlog calculations, which cannot ensure the reliability of the decision, in particular, taking into account the place and role of organizational and technological schemes for the construction of a complex of buildings and structures, as well as the accepted methods of organizing construction, which significantly affect the distribution of investment. The norms and textbooks recognize the importance of the calendar plan in the system of organizational and technological preparation of construction without specifying how to develop a calendar plan [12-17].

\section{FEATURES OF THE ORGANIZATION OF CONSTRUCTION}

IC Kishlak Qurilish Invest LLC prefers dividing the project into tranches, the implementation of which is carried out by small business entities that do not have a permanent staff of professionals. The recruitment of labor is carried out in the labor market, the professional level of which is not certified. Work on the construction of buildings, structures and communications is organized by a sequential method by an integrated brigade, in which either a combination of professions is widely practiced, or others are hired to replace some workers, which does not contribute to an increase in the quality of work and an increase in labor productivity.

The duration of the construction of the complex is determined by directive at 10 months. If the standard duration of construction of a one-story residential building made of small blocks and bricks with an area of $150 \mathrm{~m} 2$, taking into account construction conditions, is 3.5 months [18], then for a complex of
33 houses the maximum number of houses for one contractor (complex team) is 3 houses with a sequential method organization of construction. Then, for the construction of 33 houses within 10 months, it will be necessary to attract 33/3 = 11 brigades, whose work is organized in parallel. It is obvious that the involvement of a large number of contractors does not contribute to the normal organization and management of the project.

As an alternative for this case, it is possible to propose a flow organization of construction based on the specialization of the work of teams for the implementation of various stages of construction of objects.

1. Model of the organization of the construction of the complex as part of working documentation (RD)

In the above example, the construction of buildings is usually divided into four stages [18]: underground (0.5), aboveground (1.5), roof (0.5) and finishing works (1.0) are rigidly interconnected by the technological sequence in within the building $[13,19]$. With the in-line method of organizing construction, it becomes possible to perform them in parallel by specialized teams (concrete diggers; bricklayers; carpenters-roofers; plasterers-painters) in space, which will increase labor productivity. The work of teams of electricians, plumbers, gas workers is combined with the performance of basic work. On the example of the construction of 3 low-rise residential buildings, subject to the standards for the duration of the stages, it can be seen that, in comparison with the sequential method, $\mathrm{T}=(0.5+1.5$ $+1+0.5) \times 3=10.5$ months, for the flow method taking into account the organizational break between 2 and 3 works of 1.5 months, the construction period of the complex is $\mathrm{T}=(0.5+1.5+$ $1.5+0.5)+1.0 \times 3=7$ months. Further, let us assume that in order to further reduce the duration of construction, the second stage - the construction of the aboveground part will be carried out by 2 teams 
of masons, included in the construction process upon completion of stage 1 Then $T=4$ months, which is almost $57 \%$ less in comparison with the second option.

The number of brigades is traditionally determined by the compilation of the calculation of labor costs based on the bill of quantities and ENIR [9] or according to the performance indicators of the enterprise. With a known duration of work, $\mathrm{Ni}$ is determined by the following formula(1)

$N_{i}=\frac{\sum_{1}^{\rho} T_{\text {чел- }-\partial H}}{t_{i}}$

where $N_{i}$ - the number of workers in the team of the $i$-th stage;

$T_{\text {чел-дн }}$ - labor costs, people-days.;

$t_{i}$ - the duration of the $i$-th stage of building construction;

$i$ - stage numbers.

In the PPR, timetables are developed for the construction of a typical building. Considering the many contractors, the quality and their coordination with the customer becomes more difficult. In addition, as mentioned above, the relationship "customer-contractor" must be built on a single platform, and this platform is the timetable within the RD. Therefore, it is advisable to assume the need to combine the two types of schedules. First, to develop a calendar plan according to the model of the flow organization of the construction of the complex (MPSK) as in the POS [10,20,21], but the nomenclature and scope of work should be determined on the basis of the summary sheet of the scope of work and estimates. It is proposed to develop a calendar plan for the construction of an affordable housing complex in the following sequence:

- at the beginning, objects should be grouped according to their purpose and the nature of the flow. By the nature of the flow development, objects are grouped into local and linear. Local facilities are subdivided into buildings according to their purpose: residential buildings, possibly residential buildings with courtyard buildings (shed with a boiler room and a boiler); social infrastructure buildings (mini markets and banks, baths, consumer service points, etc.) and structures (transformer substation, pumping station); playgrounds, sports grounds, etc.), and the flow for the construction of communications includes all linearly extended structures (water, gas pipelines, sewers, roads, sidewalks, fences and barriers);

- compile a summary sheet of the volume of work, highlighting the main construction and installation work, the technological sequence of production of which cannot be violated within a single object;

- to form the calculated parameters: volume-labor costs-duration; cost of work. It is recommended to develop a calendar plan of the complex using the model of the flow organization of the construction of the complex, which allows achieving a number of advantages due to the minimum use of resources of the same name per unit of time and the parallel maximum use of unlike resources, gradual and rhythmic release of finished products (preparation for commissioning);

- build a cyclogram of a complex flow;

- to determine the intensity of the development of capital investments and construction and installation works;

- build differentiated, combined and integral financing schedules;

- by periods of construction (in this case, by months), determine the amount of capital investments and construction and installation works being mastered;

- calculate the amount of capital investments and construction and installation works to be mastered on an accrual basis; 
- calculate backlogs by construction periods and compare with the standard values. If the values differ by more than $1 \%$;

- repeat the calculation, having previously changed the parameters for 2 and / or 3 streams.

Considering that the duration of the deployment of the flow of construction of residential buildings can be determined from the duration of the work of the underground part of the building, in the example it is 0.5 months and the number of houses, therefore, with a minimum of performers $\tau_{1}=N \cdot 0,5$, and the period of production $T_{n p 1}=N \cdot 1,0$.

The cost of objects included in this stream is determined according to the estimate for the construction of the complex by summing the costs, for example, for the first stream as the sum of the costs of residential buildings with courtyard buildings, fencing, gates, gas, water, and electricity.

$\mathrm{P}_{\mathrm{k}}=\sum_{1}^{n} p_{i k} \cdot m_{k}$,

where $\mathrm{Pk}$ - the cost of construction and installation works of the objects included in the stream, million soums;

- the cost of the main construction and installation works that determine the duration of construction of buildings and / or structures included in the flow, the i-th object of the k-th flow, $\mathrm{mln}$.

nk - stages of construction (underground, aboveground, roofing, finishing);

mk- the number of objects in the k-th stream;

i-work numbers; $(1, \ldots, n)$;

j-object stream numbers $(1, . ., k)$.

As a result, construction participants will receive a calendar plan with the distribution of capital investments and construction and installation work in accordance with the requirements of the norms for the duration of construction and the backlog in construction [18], provided for by the norms for organizing construction [10, 20, 21], and based on its parameters, obtain information on the beginning and end of specialized streams (complex teams), the timing and need for material and technical resources, performers, etc. information for inclusion in the work contract.

The cyclogram of the complex flow with the rhythmic organization of the construction of a complex of 33 residential buildings is greatly simplified. Keeping the previous conditions of construction duration of 10 months, the operation period of each of the specialized streams is $\mathrm{t} 1=\mathrm{t} 2=\mathrm{t} 3$ $=\mathrm{t} 4=7$ months.

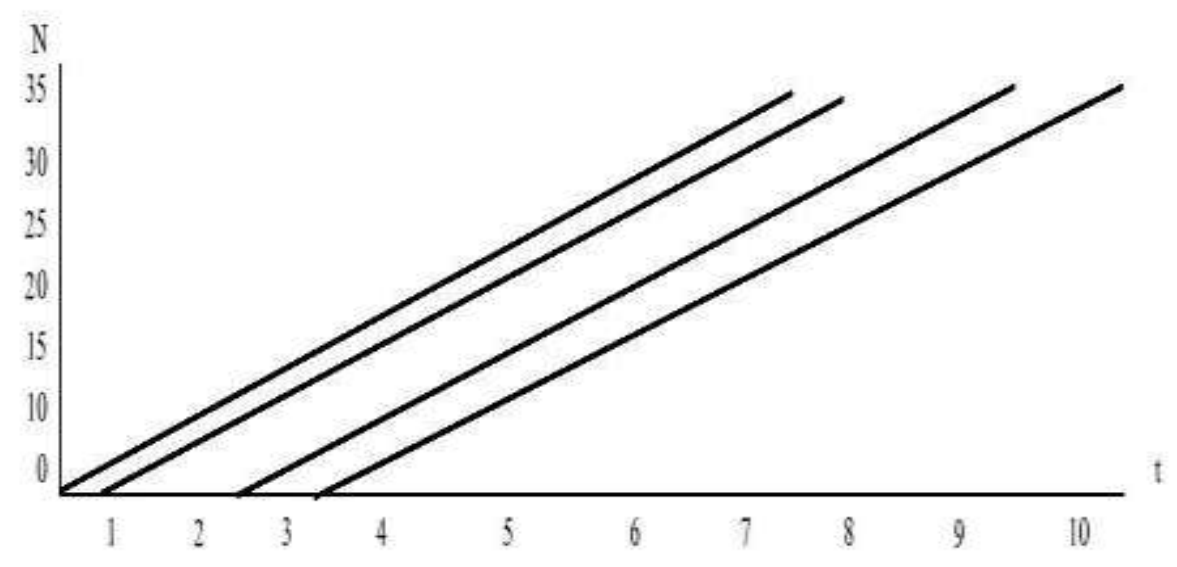

Picture 1. Cyclogram of the rhythmic flow organization of the construction of a residential area of 33 typical houses. 
In other conditions, to maintain a uniform rhythm, it is sufficient to increase the number of brigades.

The distribution of investments is built on the basis of the graph (Fig. 1). To do this, it is necessary to build a graph (Fig. 2) that differentiates between the intensity of the development of capital investments at the level of zero stage works, wall erection, roofing and finishing works. Then, the first of 33 houses will be completed by the end of 4 months. The intensity is determined by the following formula (3).

$$
I_{i}=P_{i} / t_{i}
$$

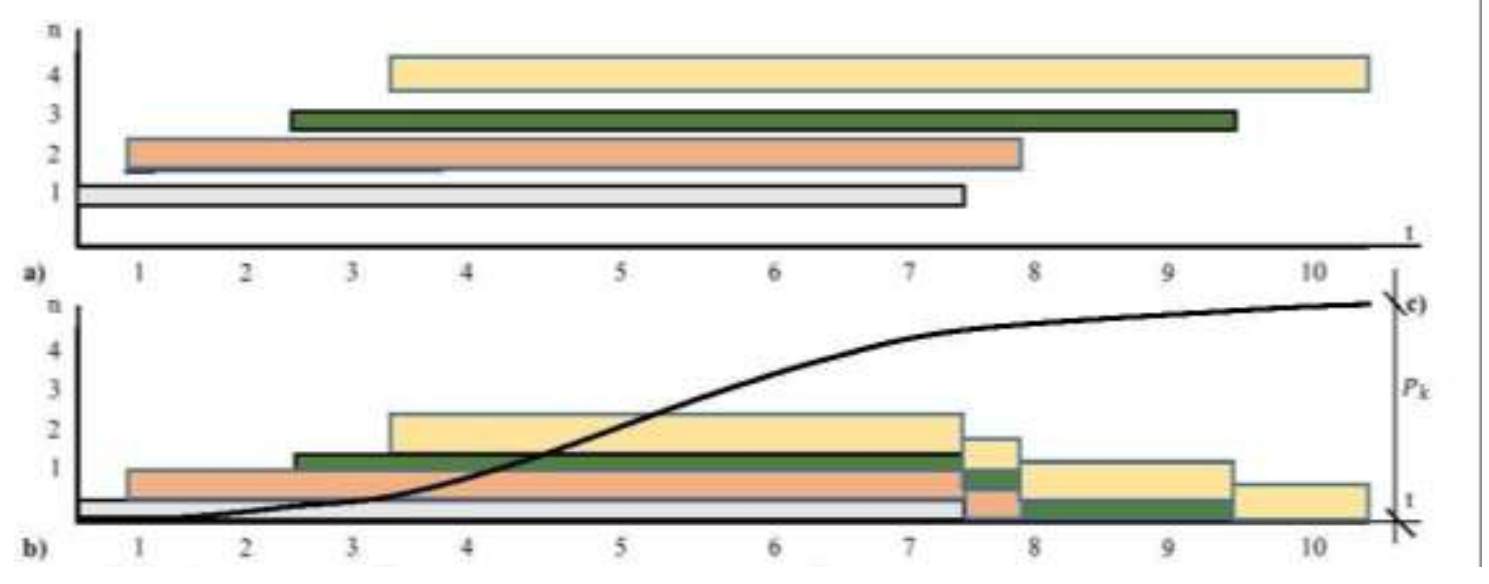

Figure-2. The schedule for the development of the volume of construction and installation works: differential (a), combined (b) and integral (c).

The overlap in time of the intensities of development in four groups of work within the first object flow determines the volume of the main construction and installation work. By summing up $\sum_{1}^{10} \sum_{1}^{4} I_{t i}$, , you can get the amount of construction and installation work by the end of the planning period, in this case, by the end of the current month. Then, with the completion of construction, an amount is formed that should be equal to the total volume of construction and installation works of the array (it should be recalled that the model takes into account only the main work that determines the duration of construction within the framework of the adopted method [18]. Whatever the method of organizing construction within one buildings, the technological sequence of works is strictly preserved).

Calculations for other object streams are performed in the same way. Expressing the results obtained as a percentage and comparing them with the backlog norms, you can make sure that the above requirements are met - the project meets the standards in terms of construction organization. A deviation of more than $1 \%$ will require a change in the design parameters and further optimization.

Thus, the schedule obtained according to the described methodology corresponds in terms of the intensity of the development of capital investments to the reserve standards. 


\section{Table 1}

Control of the calculations of the distribution of capital investments and compliance with the norms of the backlog in construction

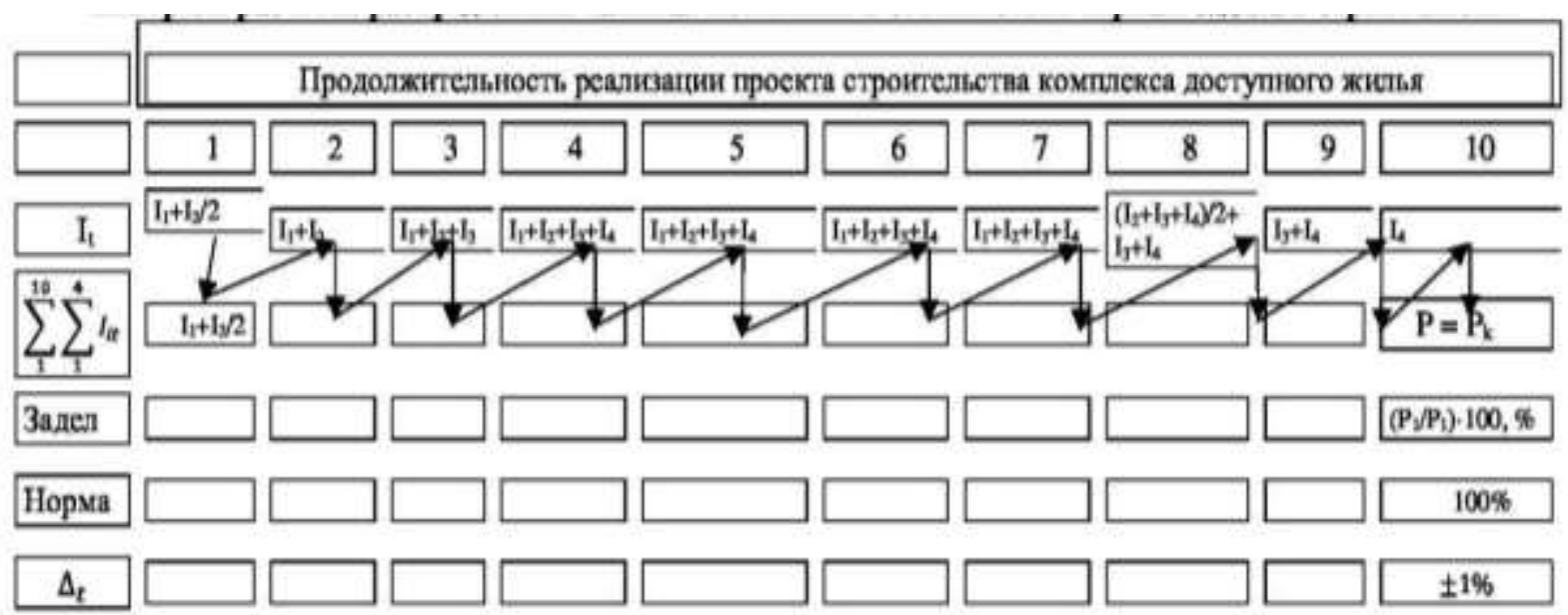

\section{CONCLUSIONS}

1. The program of affordable housing launched in early 2009 on standard projects is due, on the one hand, to significant population growth rates in Uzbekistan, compact adjoining of rural settlements to large cities, low income in rural areas, the outflow of youth to cities, on the other hand, the creation of workers places in rural areas, the tradition of a large family to provide sons with their own home with a personal plot and other circumstances of the country's social and economic development.

2. Against the background of the undoubted successes and prospects of the affordable housing program in Uzbekistan, in order to reduce costs and reduce non-productive costs, it is necessary to use the factors associated with the organization of construction. In addition, the schedule today does not have a sufficient evidence base due to the lack of a clearly defined algorithm for developing the schedule, which does not ensure the quality of the project expertise.
3. Consequently, a significant improvement of the schedule methodology is an urgent task, the demand for the development of which is also due to the need to ensure the continuity of the PIC and PPR. Then, the schedule can serve as the basis for contracting agreements, will serve as a clear relationship between the participants in the construction.

4. The methodology for developing a schedule is proposed for the conditions of construction of affordable housing complexes on the basis of the flow-based organization of work, taking into account the requirements of construction duration and backlog in construction, for which a graphic-analytical model of work is proposed in the form of a cyclogram of the complex flow of construction of an array of residential buildings.

5. The design parameters of the cyclogram are determined on the basis of the technical part of the design documentation for residential buildings, social infrastructure and facilities, their number, range and scope of work. The target dates and a number of other construction 
conditions are established from the explanatory note. The model takes into account the requirements of the norms of organization and acceptance of completed construction projects for operation.

6. The calendar plan, developed according to the proposed methodology, can be used to clarify the relevant parameters of the contract agreements, such as the financing schedule, the dates for the start and completion of work, stages, objects in space and time and the organization of construction work at the construction site.

\section{REFERENCES}

1. Resolution of the Cabinet of Ministers of the Republic of Uzbekistan No. 280 dated October 26, 2009 On measures to organize the construction of housing in rural areas on the basis of standard projects with the participation of the Qishlok Qurilish Invest engineering company.

2. Statistical Yearbook of the Republic of Uzbekistan https://stat.uz/ru/164-ofytsyalnaiastatystyka-ru/6569-

demografiya2https://stat.uz/ru/press-

tsentr/analiticheskie-stati/164-ofytsyalnaia-

statystyka-ru/6586-stroitelstvo.

3. Isakulov Sh.N. Features and trends in the development of housing construction in Uzbekistan. Institute for Social Research of the Cabinet of Ministers of the Republic of Uzbekistan // Round table on the preparation of a national survey on housing and land use. Tashkent, 2014.

4. PP-3350 of October 23, 2017 "On additional measures for the effective implementation of the Program for the construction and reconstruction of affordable apartment buildings in cities for 2017-2020."

5. PP-3550 of 20.02.2018 "On measures to improve the procedure for the examination of pre-design, project, tender documentation and contracts".

6. PP-3863 of 18.07 .2018 "On additional measures to improve the mechanisms for implementing programs for the construction of affordable residential buildings according to updated standard projects in rural areas and affordable apartment buildings in cities for 2018".

7. PP-3937 dated 09/10/2018 "On measures to implement the project" Development of engineering infrastructure in rural areas for the construction of individual housing according to standard projects "with the participation of the Kuwait Fund for Arab Economic Development.

8. PP-4028 of November 24, 2018 "On additional measures to expand the construction of affordable residential buildings in rural areas and for certain categories of citizens."

9. PP-4201 of 20.02.2019 "On additional measures for the implementation of the Obod kishlok program in 2019".

10. SHNK 3.01.01-03. Organization of construction production.

11. Ezeldin, Samer. Construction Site Coordination and Management Guide. Momentum Press, 2018.182 p.

12. Tsai TN, Grabovoi PM, Bolshakov V. Organization of construction production. Textbook for universities. M .: AVS, 1999 - 432 p.

13. Dickman, L.G. Organization of construction production: textbook / [Under the general editorship of Tsai T. and Grabovoi P. Moscow: ASV Publishing House, 2018.

14. Belova, E.M. Planning and modeling of construction production. Uch. Benefit. Kemerovo: KuzGTU, 2012 .-31p.

15. Butenko, E.A., Aksenova, N.A. Scheduling. Volgograd: VolgGTU, 2018 --124.

16. Billington, M.J. et all. The Building Regulations: Explained and Illustrated. 4th edition. - Wiley Blackwell, 2017.-1005 p. 
17. Mikhailov A.Yu. Organization of construction. Scheduling and network planning. $M$.: InfraEngineering, 2016 .-296 p.

18. SNIP 3.01.01-85 Standards for the duration of construction and backlog in the construction of enterprises, buildings and structures. Part 1 and 2/ Reprinted with amendments on June 1, 1990. M .: ROSSTROY, 1990.

19. Ching, Francis D.K., Winkel, Steven R. Building Codes Illustrated: A Guide to Understanding the
2015 International Building Code. John Wiley \& Sons, $2016 .-451 \mathrm{p}$.

20. SP 48.13330.2011 Organization of construction. M .: Ministry of Regional Development of the Russian Federation, 2011.

21. SNIP 12-01-2004 Organization of construction. M.: Gosstroy, 2005. 